\title{
INFLUenCe OF THE DESign PARAMETERS OF THE Piston MECHANISM ON THE DEAD BAND OF THE Axial-Piston Hydraulic Machine
}

\author{
Victor Elchinsky, Anton Kuzmin, Valeriy Popov \& Sergey Stazhkov
}
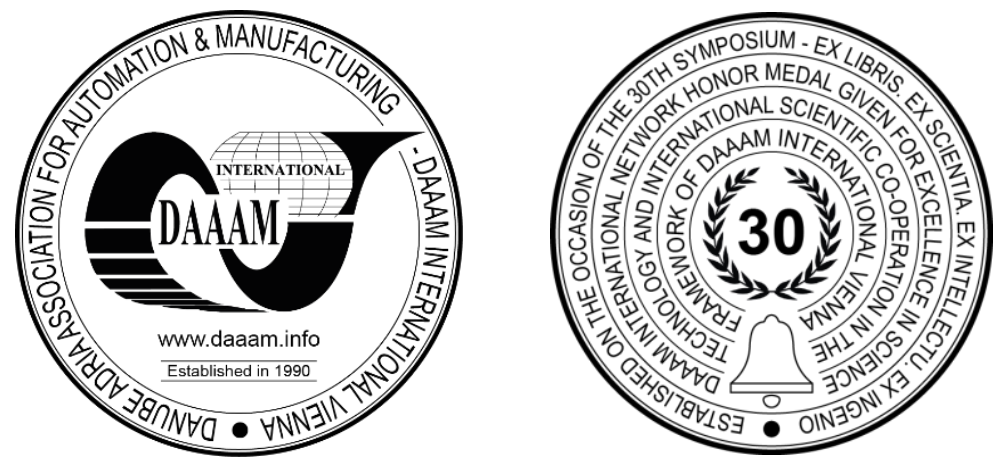

This Publication has to be referred as: Elchinsky, V[iktor]; Kuzmin, A[nton]; Popov, V[alery] \& Stazhkov, S[ergey] (2020). Influence of the Design Parameters of the Piston Mechanism on the Dead Band of the Axial-Piston Hydraulic Machine, Proceedings of the 31st DAAAM International Symposium, pp.0384-0390, B. Katalinic (Ed.), Published by DAAAM International, ISBN 978-3-902734-29-7, ISSN 1726-9679, Vienna, Austria

DOI: $10.2507 / 31$ st.daaam.proceedings.053

\begin{abstract}
Axial-piston hydraulic swash plate machines are widely used in modern positive displacement hydraulic drives, which is due to their high energy consumption and simple design. However, a large dead band significantly reduces their control range when starting and reversing. The friction force in the piston mechanism directly and its effect on volume leaks significantly affects the dead band. To solve this problem, the design of an improved piston mechanism was developed, which friction forces are significantly lower than the standard design during the operating cycle. This article presents an analysis of the influence of various parameters of the modified piston mechanism on the reduction of the friction forces. The analysis allows to evaluate the effectiveness of application of a modified design for a specific hydraulic machine or specific values of the tilt angles of the support disk. The use of a modified piston mechanism, allowing for the recommendations developed, will significantly reduce the dead band of the hydraulic drive.
\end{abstract}

Keywords: axial-piston hydraulic swash plate machine; dead band; tribology; hydraulic drive.

\section{The problem of dead band at low speeds}

In order to improve positive displacement hydraulic drives, a wide area of tasks on various issues is considered. The issues of [3] pulsation and [1] losses in a hydraulic drive are currently investigated. A relevant task in improving the positive displacement drive is to reduce the dead band of the hydraulic machine. Especially, it is crucial for hydraulic drives of servo systems. In such systems, the size of the dead band directly affects the accuracy and speed of the system. The dead band of the drive is affected by the friction forces and leakage of the working fluid [2].

In modern high-precision power drives, axial-piston hydraulic swash plate machines are widely applied. These machines have advantages in power consumption and mass-dimensional characteristics. The friction forces between the piston and the guiding bushing in motor mode creates obstacles for starting and reversing of the hydraulic machine. The friction forces are caused by the design features of the hydraulic machine and determine the dead band. In the motor mode of operation, the friction forces in the piston pair act in the direction of opening the joint between the port plate and the cylinder block. Leakage of the working fluid through the joint also affect the dead band of the hydraulic machine [4]. 
The friction forces in the piston - guiding bushing pair also affect the opening of the slipper - swash plate joint [5]. The opening of this joint increases the friction forces in the piston mechanism overall. A number of current investigations are devoted to improving the operation of the hydraulic piston pair in the nominal speed range [6]. However, in this case, hydrodynamic forces put an essential impact, which is not relevant for issues of operating at low speeds.

In previous work on the issue of the reduction of the friction forces in the piston pair an improved piston mechanism was developed [7]. For the application of this design in a swash plate machine it is required to develop the dependence of the parameters of the modified piston mechanism for different cases of operation and design of axial-piston hydraulic swash plate machine. In this paper, various force schemes of the modified piston mechanism of a hydraulic machine operating in motor mode are considered, and their comparison with the force scheme of the piston mechanism of the most commonly used design is made. The purpose of the work is to develop recommendations for the design of an improved piston mechanism that will allow to reduce the dead band of an axial-piston hydraulic swash plate machine in the motor mode of operation.

\section{Analysis of the influence of various parameters of the developed piston mechanism on the reduction of the friction forces}

To develop a hydraulic machine with the developed piston mechanism or update existing structures, a power analysis and experimental study were conducted [8]. It was found out that the application of the developed design leads to a significant reduction in the friction forces in the piston mechanism, but there are design limitations for its use. In order to study the influence of various parameters of the hydraulic machine on the effectiveness of the developed design in the more detailed way, further studies were conducted. Figure 1 shows the force scheme of the developed piston mechanism in the motor mode of operation for starting and low speeds.

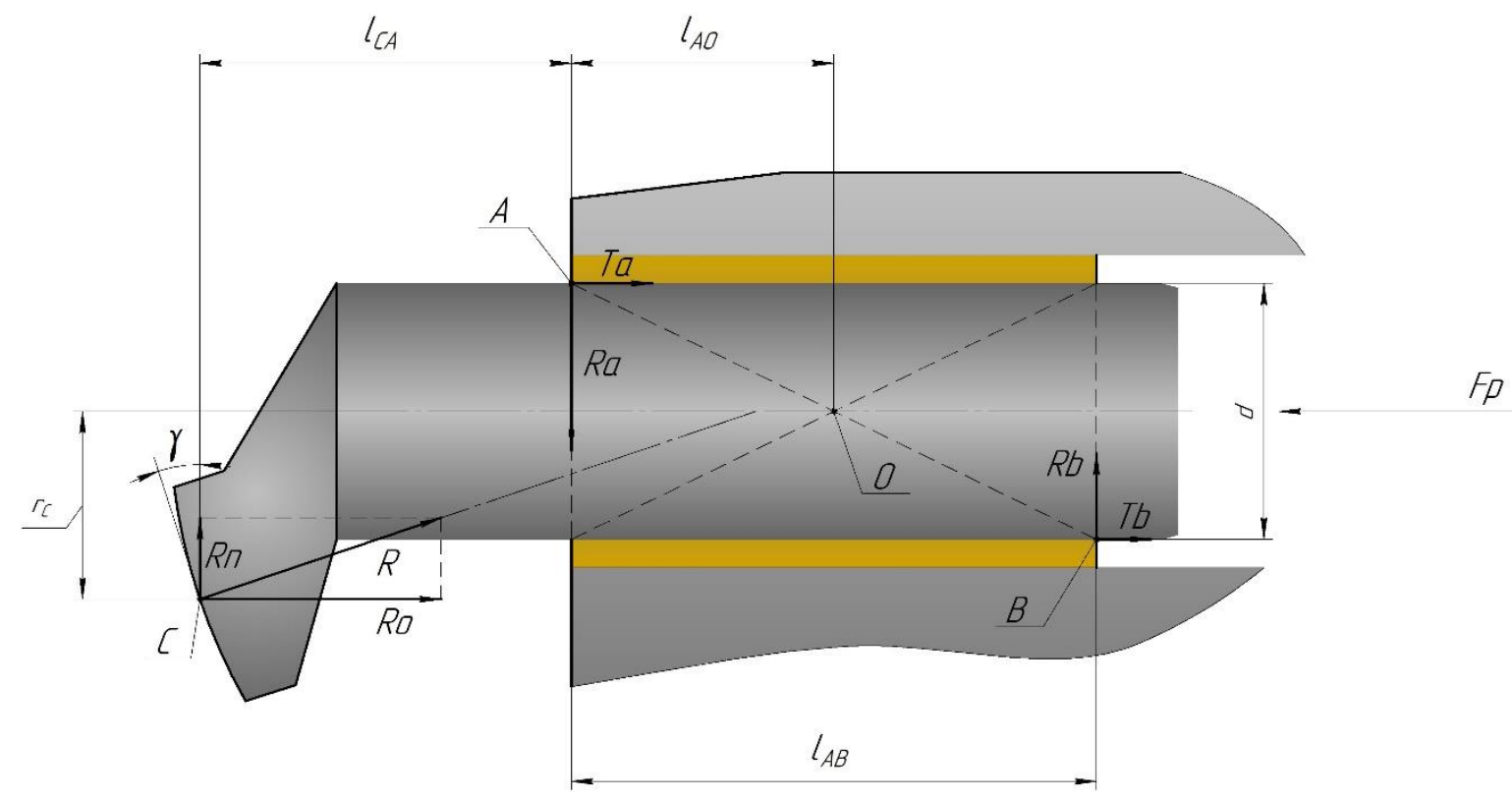

Fig. 1. Force scheme of the developed piton mechanism in the motor mode of operating

$\left(F_{P}-T\right) \cdot \operatorname{tg} \gamma \cdot\left(l_{C A}+l_{A O}\right)-\left(F_{P}-T\right) \cdot r_{C}+R_{B} \cdot f \cdot r+R_{A} \cdot f \cdot r+R_{A} \cdot l_{A O}+R_{B} \cdot l_{A O}=0$

$T=\left|R_{A} \cdot f\right|+\left|R_{B} \cdot f\right|$

$\gamma$ - swash plate tilt angle,

$f$ - friction coefficient,

$C$ - piston joint center,

$A$ - bushing reaction, $R_{A}$ application point,

$B$ - bushing reaction, $R_{B}$ application point,

$l$ - linear dimension between two points,

$r_{c}$ - piston joint displacement value,

$F_{p}$-hydrostatic pressure force, applied to the piston face, 
$R$ - swash plate reaction,

$R_{\Pi}-$ swash plate reaction transverse component,

$R_{\mathrm{o}}$ - swash plate reaction axial component,

$R_{A}$ - bushing reaction at the outer edge,

$R_{B}$ - bushing reaction at the inner edge,

$T$ - piston pair friction force in motor mode,

$T_{A}-$ piston pair friction force at the outer edge,

$T_{B}-$ piston pair friction force at the inner edge,

$d$ - piston diameter.

Considering the force scheme, reactions are calculated:

$$
\begin{gathered}
\left\{\begin{array}{c}
\left|R_{A}\right|=\left|\frac{\left(F_{p}-T\right) \cdot\left(\operatorname{tg} \gamma \cdot\left(\left(l_{C A}+l_{A B}\right)-f \cdot r\right)-r_{C}\right)}{2 l_{O A}}\right| \\
\left|R_{B}\right|=\left|\frac{\left(F_{p}-T\right) \cdot\left(\operatorname{tg} \gamma \cdot\left(l_{C A}+f \cdot r\right)-r_{C}\right)}{2 l_{O A}}\right|
\end{array}\right. \\
\left\{\begin{array}{c}
R_{A}+R_{B}=\left(F_{p}-T\right) \cdot \operatorname{tg} \gamma \\
\frac{\left|R_{A}\right|}{\left|R_{B}\right|}=\frac{\left|\operatorname{tg} \gamma \cdot\left(\left(l_{C A}+l_{A B}\right)-f \cdot r\right)-r_{C}\right|}{\mid\left(t g \gamma \cdot\left(l_{C A}+f \cdot r\right)-r_{c} \mid\right.} \\
\left|R_{A}\right|+\left|R_{B}\right|=\frac{T}{f}
\end{array}\right.
\end{gathered}
$$

There are a number of variants of the power scheme in figure 1: when the reaction vector of the swash plate intersects the axis of the guiding bushing from the outer face of the bushing; when the reaction vector intersects the axis of the guiding bushing from the inner face of the bushing; when the reaction vector intersects the axis inside the bushing, and intermediate options. Therefore, a formula is required that allows to determine the displacement of the piston joint, that provides an absence of the piston tilt. That formula should be applied for various design parameters of the hydraulic machine throughout the entire operation cycle. As the friction force depends linearly on the reaction of the bushing:

$$
\begin{aligned}
& \left|R_{A}\right| \cdot l_{A B}=\left(F_{p}-T\right) \cdot\left|\left(\operatorname{tg} \gamma \cdot\left(\left(l_{C A}+l_{A B}\right)-f \cdot r\right)-r_{C}\right)\right| \\
& \left|R_{A}\right| \cdot l_{A B}=\left|\left(\operatorname{tg} \gamma \cdot\left(\left(l_{C A}+l_{A B}\right)-f \cdot r\right)-r_{C}\right)\right| \cdot\left(F_{p}-f \cdot\left|R_{A}\right| \cdot\left(1+\frac{\left|\operatorname{tg} \gamma \cdot\left(l_{C A}+f \cdot r\right)-r_{C}\right|}{\mid\left(\operatorname{tg} \gamma \cdot\left(l_{C A}+l_{A B}-f \cdot r\right)-r_{C} \mid\right.}\right)\right) \\
& \left|R_{A}\right| \cdot\left(l_{A B}+\left|\operatorname{tg} \gamma \cdot\left(\left(l_{C A}+l_{A B}\right)-f \cdot r\right)-r_{C}\right| \cdot f \cdot\left(1+\frac{\left|\operatorname{tg} \gamma \cdot\left(l_{C A}+f \cdot r\right)-r_{C}\right|}{\mid\left(\operatorname{tg} \gamma \cdot\left(l_{C A}+l_{A B}-f \cdot r\right)-r_{C} \mid\right.}\right)\right)=F_{p} . \\
& \left|\operatorname{tg} \gamma \cdot\left(\left(l_{C A}+l_{A B}\right)-f \cdot r\right)-r_{C}\right|
\end{aligned}
$$

From (7), the ratio of the friction force and the dimensionless value - the relative friction force related to the force of pressure on the end of the piston - is obtained:

$$
T=T^{0} \cdot F_{p}
$$

Substituting the absolute values of the reactions in the expression for the friction force:

$$
\begin{aligned}
& T^{0} \cdot F_{p} \cdot \frac{l_{A B}}{f}=\left(F_{p}-T^{0} \cdot F_{p}\right) \cdot\left(\left|\operatorname{tg} \gamma \cdot\left(\left(l_{C A}+l_{A B}\right)-f \cdot r\right)-r_{C}\right|+\mid\left(\operatorname{tg} \gamma \cdot\left(l_{C A}+f \cdot r\right)-r_{C} \mid\right)\right. \\
& T^{0}=\frac{\left|\operatorname{tg\gamma } \cdot\left(\left(l_{C A}+l_{A B}\right)-f \cdot r\right)-r_{C}\right|+\mid\left(\operatorname{tg} \gamma \cdot\left(l_{C A}+f \cdot r\right)-r_{C} \mid\right.}{\frac{l_{A B}}{f}+\left|\operatorname{tg} \gamma \cdot\left(\left(l_{C A}+l_{A B}\right)-f \cdot r\right)-r_{C}\right|+\mid\left(\operatorname{tg} \gamma \cdot\left(l_{C A}+f \cdot r\right)-r_{C} \mid\right.}
\end{aligned}
$$

$T^{0}$ is the relative friction force for low-speed modes.

For the pump mode of operation, the direction of action of the friction forces in the piston pair will change: 


$$
\begin{aligned}
& \left\{\begin{array}{l}
\left|R_{A}\right|=\left|\frac{\left(F_{p}+T\right) \cdot\left(\operatorname{tg} \gamma \cdot\left(\left(l_{C A}+l_{A B}\right)+f \cdot r\right)-r_{C}\right)}{2 l_{O A}}\right| \\
\left|R_{B}\right|=\left|\frac{\left(F_{p}+T\right) \cdot\left(\operatorname{tg} \gamma \cdot\left(l_{C A}-f \cdot r\right)-r_{C}\right)}{2 l_{O A}}\right|
\end{array}\right. \\
& T^{0} \cdot F_{p} \cdot \frac{l_{A B}}{f}=\left(F_{p}+T^{0} \cdot F_{p}\right) \cdot\left(\left|\operatorname{tg} \gamma \cdot\left(\left(l_{C A}+l_{A B}\right)+f \cdot r\right)-r_{C}\right|+\mid\left(\operatorname{tg} \gamma \cdot\left(l_{C A}-f \cdot r\right)-r_{C} \mid\right)\right. \\
& T^{0}=\frac{\left|\operatorname{tg} \gamma \cdot\left(\left(l_{C A}+l_{A B}\right)+f \cdot r\right)-r_{C}\right|+\mid\left(\operatorname{tg} \gamma \cdot\left(l_{C A}-f \cdot r\right)-r_{C} \mid\right.}{\frac{l_{A B}}{f}-\left|\operatorname{tg} \gamma \cdot\left(\left(l_{C A}+l_{A B}\right)+f \cdot r\right)-r_{C}\right|-\mid\left(\operatorname{tg} \gamma \cdot\left(l_{C A}-f \cdot r\right)-r_{C} \mid\right.}
\end{aligned}
$$

The validity of the obtained formula is confirmed by the values of this coefficient obtained using iterative calculations. The values of the reactions at the edges of the bushing are calculated through using the cycle, causing the value of the friction force is obtained automatically after a certain number of iterations according to (3). Using (10) and (13), the influence of different hydraulic machine parameters on friction in the piston mechanism was researched. The analysis of parameters is of particular importance for the motor mode of operation. Figure 2 shows the dependence of $T^{0}$ on the displacement $r_{c}$ of the joint for the motor mode at the following fixed values: the swash plate tilt angle $\gamma=18^{\circ}$, the radius of the piston $=10.3 \mathrm{~mm}$, the length of the guiding bushing $=38 \mathrm{~mm}$, the stroke of the piston is $25 \mathrm{~mm}$, the initial distance $l_{C A}=8 \mathrm{~mm}$.

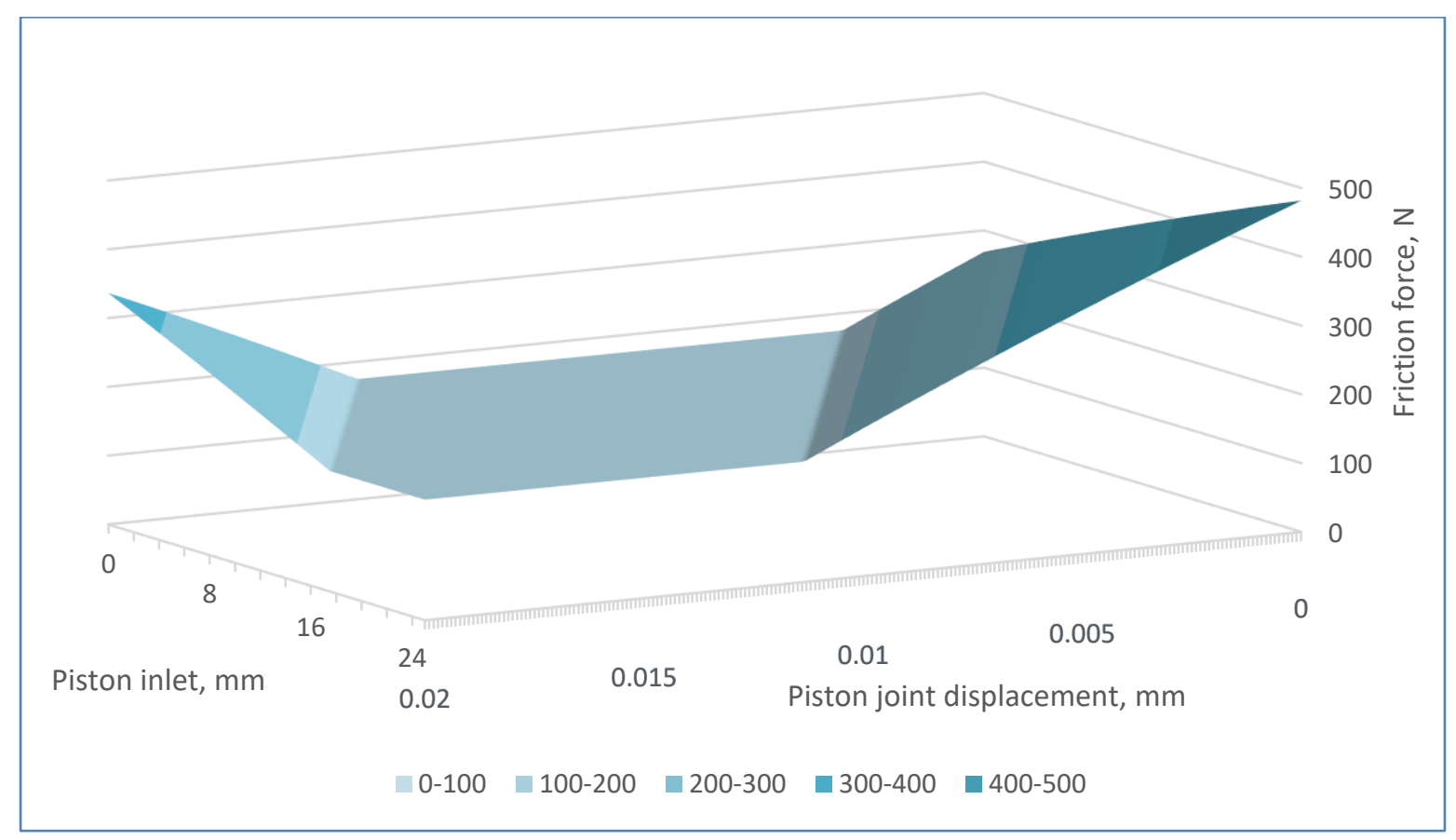

Fig. 2. Dependence of the friction force on the piston inlet and the joint displacement in the motor mode

From the analysis of the diagram in figure 2, it follows that there is a certain range of values for the displacement of the piston joint, which provides a minimum value of the friction force regardless of the piston departure. This range of values is found after comparing the minimum and maximum piston inlet values. Analysis of the graphs in figure 3 shows that at the tilt angle of $\gamma=18^{\circ}$ if the piston joint is displaced from 11 to $14 \mathrm{~mm}$, the friction force takes the lowest value and does not depend on the piston inlet. It means that the joint displacement in this range is preferred. Taking into account the absence of displacement of the piston head in the standard piston mechanism $\left(r_{c}=0\right)$, the parameter $\mathrm{K}$ is calculated and expresses the ratio of the friction forces of the standard piston mechanism to the friction forces of the developed piston mechanism, using the following formula:

$$
\begin{aligned}
K=\frac{T_{s t}}{T_{d e v}}= & \frac{\left(\left|\operatorname{tg} \gamma \cdot\left(\left(l_{C A}+l_{A B}\right)-f \cdot r\right)\right|+\mid\left(\operatorname{tg} \gamma \cdot\left(l_{C A}+f \cdot r\right) \mid\right) \cdot\right.}{\left(\frac{l_{A B}}{f}+\left|\operatorname{tg} \gamma \cdot\left(\left(l_{C A}+l_{A B}\right)-f \cdot r\right)\right|+\mid\left(\operatorname{tg} \gamma \cdot\left(l_{C A}+f \cdot r\right) \mid\right) \cdot\right.} \\
& \frac{\left(\frac{l_{A B}}{f}+\left|\operatorname{tg} \gamma \cdot\left(\left(l_{C A}+l_{A B}\right)-f \cdot r\right)-r_{C}\right|+\mid\left(\operatorname{tg} \gamma \cdot\left(l_{C A}+f \cdot r\right)-r_{c} \mid\right)\right.}{\left(\left|\operatorname{tg} \gamma \cdot\left(\left(l_{C A}+l_{A B}\right)-f \cdot r\right)-r_{c}\right|+\mid\left(\operatorname{tg} \gamma \cdot\left(l_{C A}+f \cdot r\right)-r_{c} \mid\right)\right.}
\end{aligned}
$$




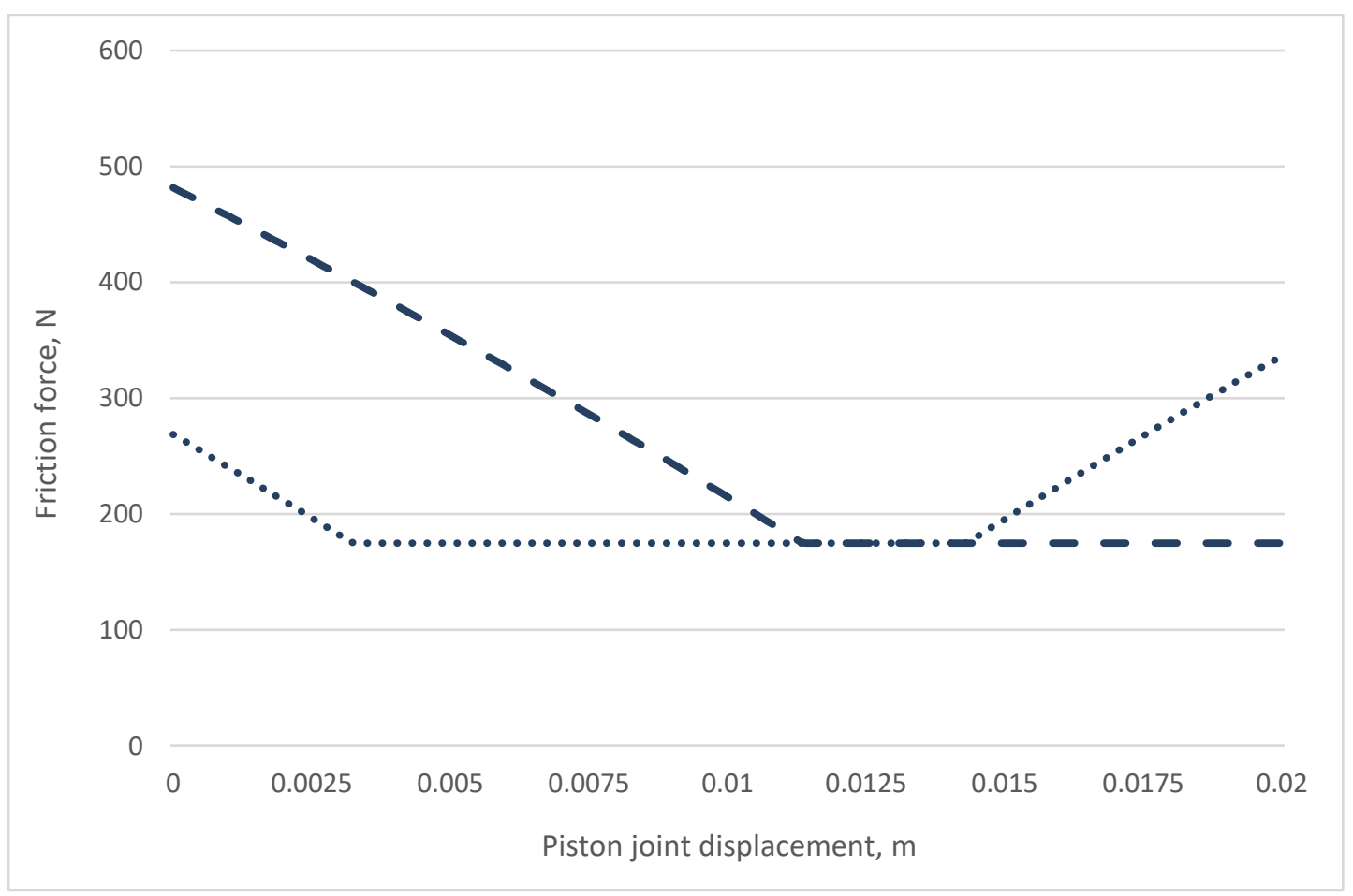

Fig. 3. Dependence of the friction force on the displacement of the piston joint at the maximum and minimum piston inlet

The higher the value of this parameter, the greater the reduction of friction forces provided by the developed design of the piston mechanism. This parameter allows you to determine the range of preferred values for the displacement of the piston joint. From the analysis of figure 4, it follows that changes in the length of the bushing and the radius of the piston do not significantly affect $\mathrm{K}$. So for the standard size of a hydraulic machine with a piston radius of $10.3 \mathrm{~mm} \mathrm{K=}$ 2.41 , and for the standard size of a hydraulic machine with a piston radius of $7.42 \mathrm{~mm} \mathrm{~K}=2.47$. Consequently, the use of the developed piston mechanism is almost equally effective for hydraulic machines of different volumes and does not require major changes in their design.

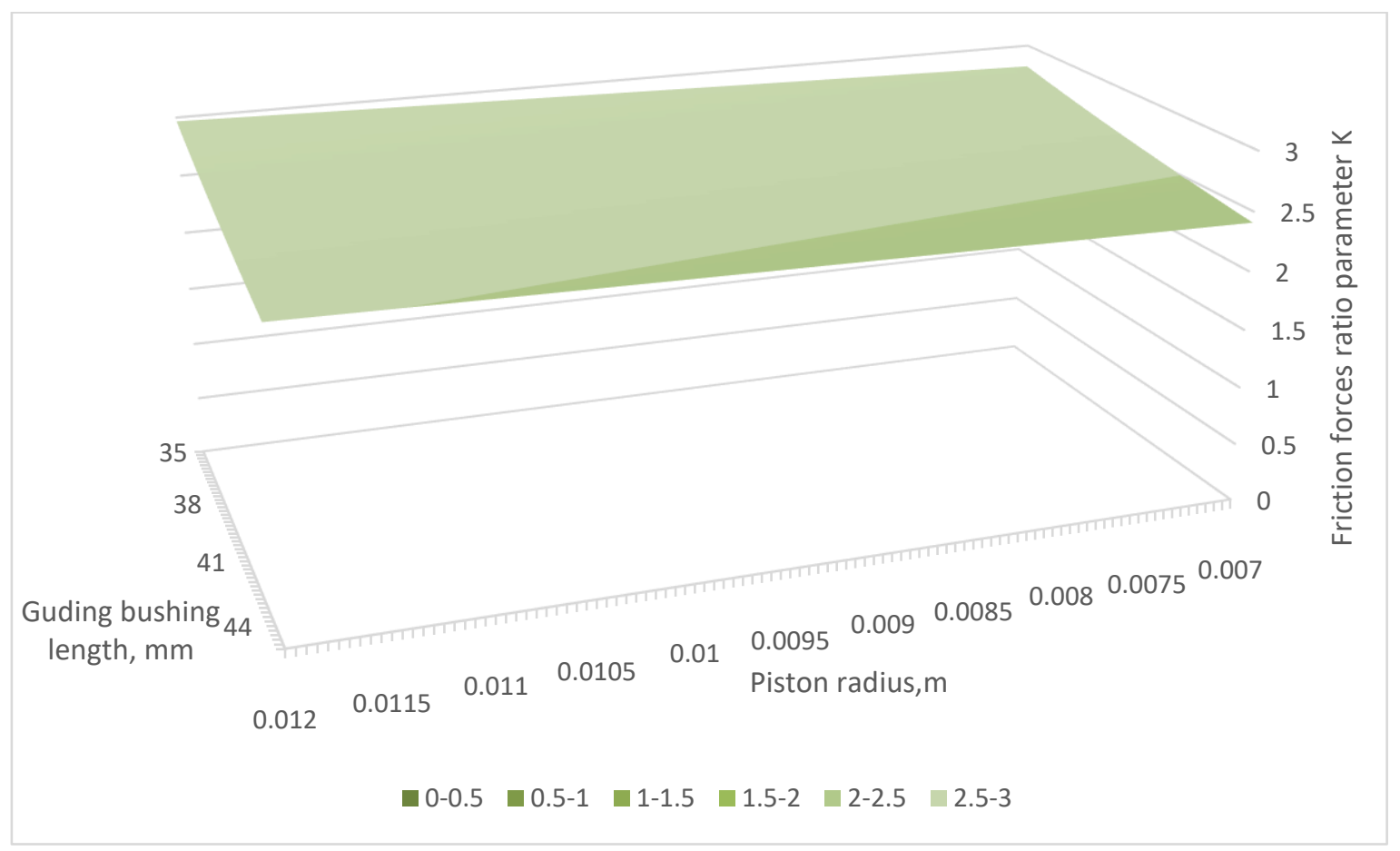

Fig. 4. Parameter of the ratio of friction forces K depending on the length of the guiding bushing and the radius of the piston 
The influence of the tilt angle of the swash plate on the value of the parameter $\mathrm{K}$ was calculated, the results of which are shown in figure 5. The calculation is performed for the maximum inlet of the hydraulic machine piston of this volume.

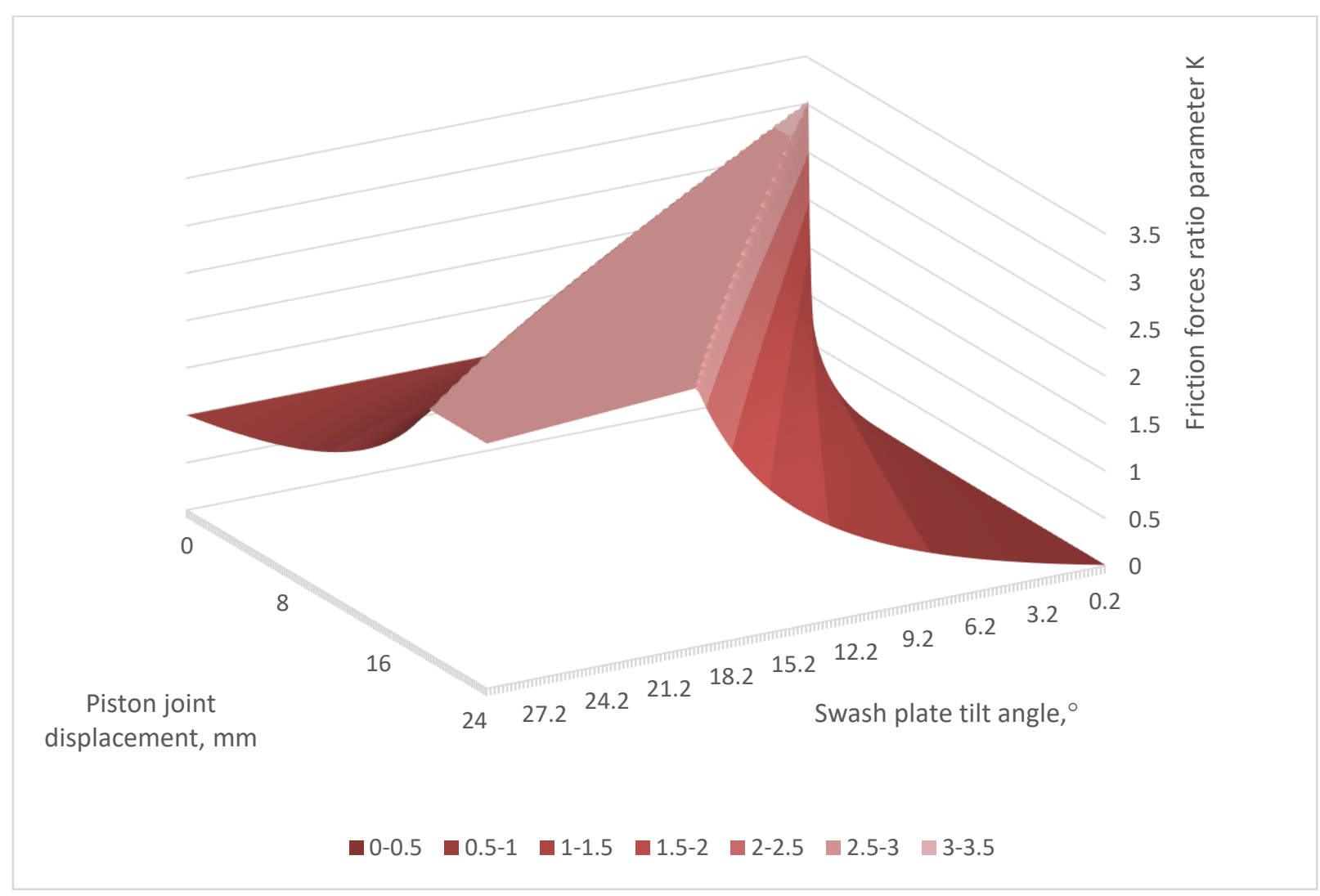

Fig. 5. Parameter of the ratio of friction forces K depending on the displacement of the piston joint and the tilt angle of the swash plate

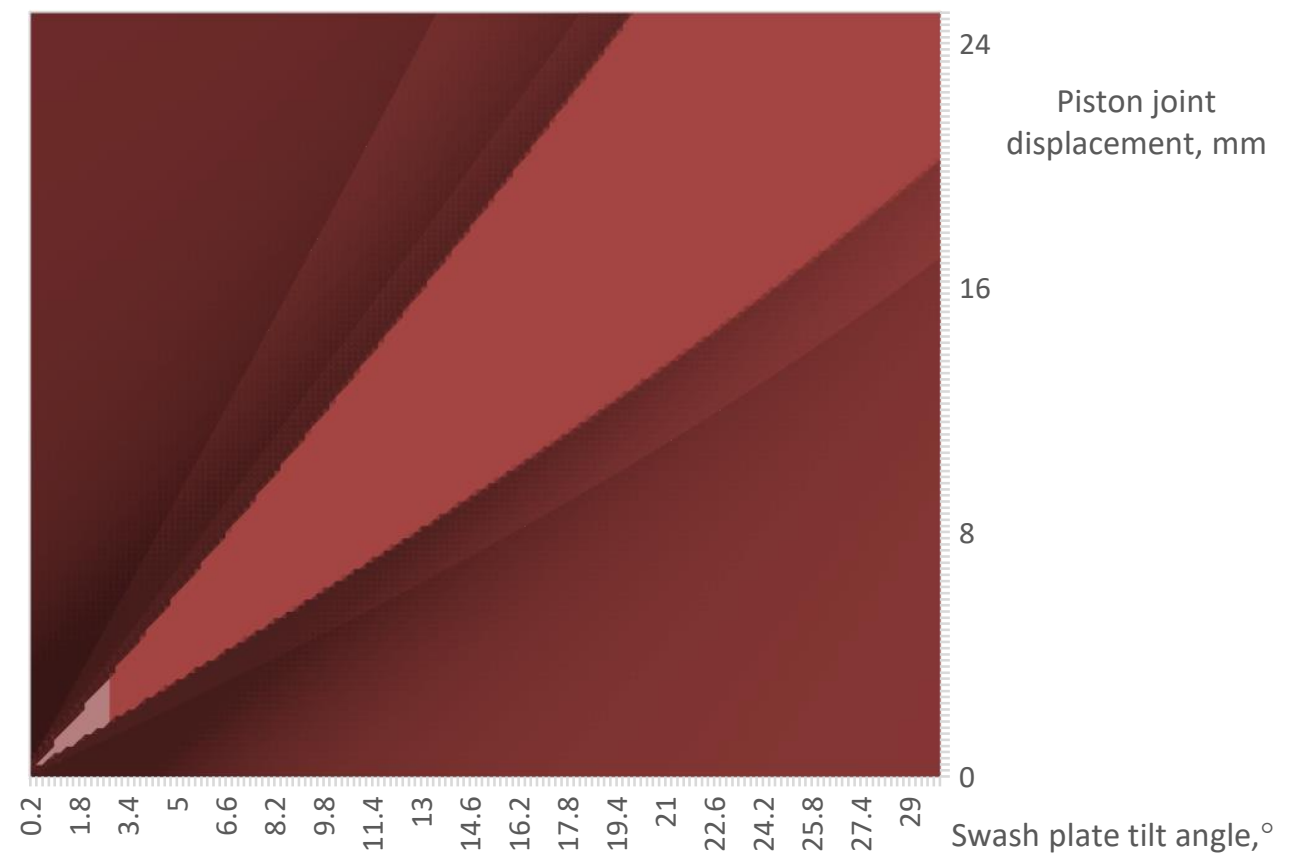

Friction forces

ratio parameter $\mathrm{K} \quad$ 0-1 $\square$ 1-2 $\square$ 2-3 $\square$ 3-4

Fig. 6. Parameter of the ratio of friction forces K depending on the displacement of the piston joint and the tilt angle of the swash plate, view from above 
Figures 5,6 show that for the displacement of the piston joint in $13 \mathrm{~mm}$, the friction forces are reduced by 2.86 times at the tilt angle $\gamma=11^{\circ}$. In the range from $\gamma=9.6^{\circ}$ to $\gamma=24.2^{\circ}$, the parameter $\mathrm{K}$ takes a value of at least 2 . Therefore, in the range from $\gamma=9^{\circ}$ to $\gamma=25^{\circ}$ the displacement of the piston joint from 11 to $14 \mathrm{~mm}$ is the most effective. The range of displacements for the small swashing plate tilt angles, which provide the greatest reduction in friction forces, is close to the zero and represents a narrow range of values.

As it shown in [8], the minimum tilt angle of the swash plate is $16^{\circ}$. With the increase of the swashing plate tilt angle, the range of values of the piston joint displacement increases. However, the minimum displacement increases as well. This introduces significant limitations due to the design features of the hydraulic machine. The displacement of more than $14 \mathrm{~mm}$ for this size of swash plate machines involves changes in the design of hydraulic machine. It affects the reliability of elements and manufacturability, in particular, leads to a decrease in the diameter of the shaft of the hydraulic machine. Based on the presented calculations and design features, the range of tilt angles of the swash plate, for which the modified piston mechanism is applicable, and it lies in the range of $16 \ldots 20^{\circ}$.

\section{Conclusion}

A significant disadvantage of the axial-piston hydraulic machine is its large dead band. In order to reduce the friction forces in the piston - guide bushing pair, and, consequently, to reduce the dead band of the hydraulic machine, a developed piston mechanism was designed, manufactured and examined.

The analysis allows to evaluate the effectiveness of application of the developed piston design for a specific hydraulic swash plate machine or specific values of the tilt angles of the swash plate, which will significantly simplify further research in this direction. The obtained dependencies allow to develop recommendations for the application of the developed design of the piston mechanism. Considering these recommendations, more than 2 times comparing with the standard design can reduce the friction forces in the modified piston mechanism. This will significantly reduce the dead band of the hydraulic drive as a whole. In further research, it is planned to create the axial-piston hydraulic swash plate machine using the developed design of the piston mechanism. It is planned to conduct research on its characteristics, paying special attention to the dead band.

\section{References}

[1] Grzegorz Skorek (2019). Determination of Coefficients of Energy Losses Occurring in a Constant Capacity Pump Working in a Typical Hydrostatic Drive, Journal of KONES Powertrain and Transport, Vol. 26, No. 1, DOI: 10.2478/kones-2019-0019

[2] Mengdi Gao, Haihong Huang, Xinyu Li, Zhifeng Liu (2016). A Novel Method to Quickly Acquire the Energy Efficiency for Piston Pumps, Journal of Dynamic Systems, Measurement, and Control, Vol. 138, DOI: $10.1115 / 1.4033840$

[3] Paolo Casoli, Mirko Pastori, Fabio Scolari and Massimo Rundo (2019). Active Pressure Ripple Control in Axial Piston Pumps through High-Frequency Swash Plate Oscillations-A Theoretical Analysis, Energies - Open Access Journal, MDPI, DOI: 10.3390/en12071377

[4] Bashta T, Rudnev S, Nekrasov B. and others (1982). Hydraulics, hydraulic machines and hydraulic drives: Textbook for engineering universities, 2nd ed., revised - M.: Maschinostroenie, $423 \mathrm{p}$.

[5] Junjie Zhou, Jichen Zhou \& Chongbo Jing (2020). Experimental Research on the Dynamic Lubricating Performance of Slipper/Swash Plate Interface in Axial Piston Pumps, Chinese Journal of Mechanical Engineering. 33, Article number: 25

[6] Matteo Pelosi (2012). An Investigation on the Fluid-Structure Interaction of Piston/Cylinder Interface, Ph.D. Dissertation, Purdue University, West Lafayette, Indiana, USA

[7] Stazhkov, S[ergey]; Korobova, I[raida]; Korolev, V[ladimir] \& Kuzmin, A[nton] (2019). Hydrodynamic Processes Research of the Positive Displacement Hydraulic Machines Piston Interface, Proceedings of the 30th DAAAM International Symposium, pp.0580-0585, B. Katalinic (Ed.), Published by DAAAM International, ISBN 978-3902734-22-8, ISSN 1726-9679, Vienna, Austria

[8] Kuzmin, A[nton]; Popov, V[alery] \& Stazhkov, S[ergey] (2016). Advanced Axial Piston Swash Plate Pump Parameters Recommendations, Proceedings of the 27th DAAAM International Symposium, pp.0556-0561, B. Katalinic (Ed.), Published by DAAAM International, ISBN 978-3-902734-08-2, ISSN 1726-9679, Vienna, Austria 